University of Nebraska - Lincoln

DigitalCommons@University of Nebraska - Lincoln

$2-2003$

\title{
Size-Abundance Relationships in an Amazonian Bird Community: Implications for the Energetic Equivalence Rule
}

\author{
Sabrina E. Russo \\ University of Nebraska - Lincoln, srusso2@unl.edu \\ Scott K. Robinson \\ University of Illinois at Urbana-Champaign \\ John Terborgh \\ DukeUniversity, manu@duke.edu
}

Follow this and additional works at: https://digitalcommons.unl.edu/bioscifacpub

Russo, Sabrina E.; Robinson, Scott K.; and Terborgh, John, "Size-Abundance Relationships in an Amazonian Bird Community: Implications for the Energetic Equivalence Rule" (2003). Faculty Publications in the Biological Sciences. 253.

https://digitalcommons.unl.edu/bioscifacpub/253

This Article is brought to you for free and open access by the Papers in the Biological Sciences at DigitalCommons@University of Nebraska - Lincoln. It has been accepted for inclusion in Faculty Publications in the Biological Sciences by an authorized administrator of DigitalCommons@University of Nebraska - Lincoln. 


\title{
Size-Abundance Relationships in an Amazonian Bird Community: Implications for the Energetic Equivalence Rule
}

\author{
Sabrina E. Russo, ${ }^{1, *}$ Scott K. Robinson, ${ }^{1}$ and John Terborgh ${ }^{2}$
}

1. Department of Animal Biology, University of Illinois, Urbana, Illinois 61801;

2. Center for Tropical Conservation, Duke University, P.O. Box 90381, Durham, North Carolina 27708-0381

Submitted May 10, 2001; Accepted August 27, 2002; Electronically published February 5, 2003

\begin{abstract}
We studied size-abundance relationships in a speciesrich Amazonian bird community and found that the slope of the logarithmic relationship between population density and body mass $(b=-0.22)$ is significantly shallower than expected under Damuth's energetic equivalence rule (EER), which states that population energy use (PEU) is independent of species body mass. We used estimates of avian field metabolic rates to examine the logarithmic relationship between PEU and body mass and its variation among ecological guilds. The relationship for all species had a significantly positive slope $(b=0.46)$, indicating that PEU of larger species was greater than that of smaller species. Analyses of guilds revealed significant variation. The slopes of the frugivore-omnivore, insectivore, and granivore guilds were all significantly positive, with that of the frugivore-omnivore guild being the steepest. In contrast, PEU did not vary significantly with species body mass among raptors. These results were confirmed in analyses using both species values and phylogenetically independent contrasts, and the results do not support the EER in this community. The spatial distribution of resources and mechanisms of interference competition within guilds may explain why most patterns differed from the predictions of the EER. Other sources of variation, including the effects of scale, are also discussed.
\end{abstract}

Keywords: energetic equivalence rule, Neotropics, avian community structure, body mass, population density, phylogenetically independent contrasts.

\footnotetext{
* E-mail: srusso@uiuc.edu.
}

Am. Nat. 2003. Vol. 161, pp. 267-283. (c) 2003 by The University of Chicago. 0003-0147/2003/16102-010172\$15.00. All rights reserved.
The relationship between body size and population density has been extensively examined because it has broad implications for the structure of and energy flow in ecological communities (Damuth 1981, 1987; Brown and Maurer 1987; Pagel et al. 1991; Illius and Gordon 1992; Taper and Marquet 1996), geographic range size (Brown and Maurer 1987; Gaston and Blackburn 1996), patterns of biodiversity and evolution (Brown and Maurer 1986, 1987; Damuth 1993; Siemann et al. 1996), and the generality and potential theoretical underpinnings of allometric scaling laws (Morse et al. 1985; Dobson and Headrick 1995; West et al. 1997; Enquist et al. 1998; Ritchie and Olff 1999; Enquist and Niklas 2001, 2002). Damuth $(1981,1987)$ investigated the logarithmic relationship between body mass and population density for mammals spanning several orders of magnitude in size, and he found a slope of -0.75 . The negative slope has been suggested to reflect metabolic processes; that is, larger animals should have lower population densities because they use more energy per capita per unit time (Peters 1983). Because the logarithmic relationship between mammals' resting metabolic rate and body mass has an estimated slope of 0.75 (Peters 1983), Damuth (1981, 1987) proposed the energetic equivalence rule (EER). This rule states that the energy used by a species' local population (population energy use [PEU]) is independent of its body mass. Energetic constraints may therefore influence the structure of ecological communities (Damuth 1981, 1987), such as by placing an upper limit on the population densities of large species.

If the EER is a more general rule of community structure (Damuth 1981, 1987), then it may be expected to apply at the community scale, as well as at regional or global scales. In such a case, the absolute value of the slope of the size-abundance relationship should not be significantly different from the slope of the logarithmic relationship between body mass and field metabolic rate (FMR) for a given assemblage of species. Scrutiny of the sizeabundance relationship in animals, however, shows variation across taxonomic, spatial, and geographic scales, but 
Table 1: Chronological summary from the literature of ordinary least squares regression statistics of the logarithmic relationship between body mass and population density for birds

\begin{tabular}{|c|c|c|c|c|c|c|c|}
\hline Region & Guild $^{\mathrm{a}}$ & Slope & $95 \% \mathrm{CI}^{\mathrm{b}}$ & $R^{2}$ & $n^{c}$ & Probability & Reference \\
\hline North America & All guilds & -.19 & $(-.47, .09)$ & .03 & 60 & $>.05$ & Peters and Wassenberg 1983 \\
\hline North America & Herbivores & .21 & $(-.21, .63)$ & .05 & 22 & $>.05$ & Peters and Wassenberg 1983 \\
\hline North America & Carnivores & -.52 & $(-.89,-.16)$ & .18 & 38 & $<.05$ & Peters and Wassenberg 1983 \\
\hline North America & All guilds & -.30 & $N^{d}$ & $N G^{\mathrm{d}}$ & 197 & $\mathrm{NG}^{\mathrm{d}}$ & Brown and Maurer 1986 \\
\hline North America & All guilds & -.49 & $(-.57,-.40)$ & .18 & 564 & .0001 & Juanes 1986 \\
\hline North America & Herbivores & -.02 & $(-.20, .16)$ & .001 & 56 & .81 & Juanes 1986 \\
\hline North America & Omnivores & -.23 & $(-.60,-.14)$ & .03 & 47 & .22 & Juanes 1986 \\
\hline North America & Insectivores & -.31 & $(-.40,-.22)$ & .09 & 442 & .001 & Juanes 1986 \\
\hline North America & Raptors & -2.22 & $(-3.18,-1.26)$ & .58 & 19 & .001 & Juanes 1986 \\
\hline North America & All guilds & -.09 & $(-.15,-.02)$ & .02 & 380 & $<.05$ & Brown and Maurer 1987 \\
\hline Great Britain & All guilds & -.75 & $(-1.06,-.44)$ & .14 & 147 & .0001 & Nee et al. 1991 \\
\hline Sweden & All guilds & -.77 & $(-1.00,-.54)$ & .18 & 206 & .0001 & Nee et al. 1991 \\
\hline Global & All guilds & -.60 & $N^{\mathrm{d}}$ & .15 & 437 & .0001 & Cotgreave and Harvey 1992 \\
\hline Great Britain & All guilds ${ }^{\mathrm{e}}$ & -.57 & $\mathrm{NG}^{\mathrm{d}}$ & .08 & 175 & .0002 & Blackburn et al. 1994 \\
\hline Ireland & All guilds $\mathrm{e}^{\mathrm{e}}$ & -.74 & $N G^{d}$ & .11 & 149 & .0002 & Blackburn et al. 1994 \\
\hline Panama & All guilds & -.25 & $\mathrm{NG}^{\mathrm{d}}$ & .05 & 25 & .30 & Brawn et al. 1995 \\
\hline Australia & All guilds & -.82 & $(-.97,-.66)$ & .35 & 200 & .001 & Cotgreave 1995 \\
\hline Australia & Nonpasserines & -1.03 & $(-1.52,-.97)$ & .27 & 57 & .0001 & Cotgreave 1995 \\
\hline Australia & Passerines & -.42 & $(-.36,-.17)$ & .11 & 143 & .0001 & Cotgreave 1995 \\
\hline Great Britain & All guilds & -.57 & $N G^{\mathrm{d}}$ & $N G^{\mathrm{d}}$ & 156 & .0001 & Gregory 1995 \\
\hline Great Britain & Nonpasserines & -.31 & $N G^{\mathrm{d}}$ & $N G^{\mathrm{d}}$ & 79 & .04 & Gregory 1995 \\
\hline Great Britain & Passerines & -.23 & $\mathrm{NG}^{\mathrm{d}}$ & $\mathrm{NG}^{\mathrm{d}}$ & 77 & .15 & Gregory 1995 \\
\hline Great Britain & All guilds & -.79 & $(-1.12,-.45)$ & .13 & 144 & .001 & Greenwood et al. 1996 \\
\hline Great Britain & All guilds ${ }^{\mathrm{e}}$ & -1.43 & $(-2.21,-.64)$ & .21 & 51 & .001 & Greenwood et al. 1996 \\
\hline
\end{tabular}

a All studies are of resident breeding birds, except where otherwise noted.

b The $95 \%$ confidence interval (95\% CI) for each slope is given. When the $95 \%$ CI was not reported, it was calculated from the reported standard error of the regression slope and sample size.

c The sample size $(n)$ is the number of species.

d NG means "not given."

e Study was of wintering migrants.

the mechanisms underlying the relationship and its variation remain obscure (Cotgreave 1993; Blackburn and Gaston 1997; Marquet 2000). Patterns in size-abundance relationships in plants tend to be more consistent across multiple scales (Enquist et al. 1998, 1999; Enquist and Niklas 2002). Although many analyses of size-abundance relationships in animals use global- or regional-scale data sets compiled from the literature, many workers have suggested that smaller-scale analyses, such as at the level of complete communities, may be more likely to reveal mechanisms responsible for patterns in size-abundance relationships (Blackburn et al. 1990, 1993a). Patterns at smaller scales of analysis, however, tend to be more variable and to show less statistically significant relationships than ones at larger scales (Currie 1993; Blackburn and Gaston 1997), particularly in birds (Peters and Wassenberg 1983).

A recent estimate of the slope of the logarithmic relationship between body mass and FMR for birds is 0.681 ( $95 \%$ confidence interval $[\mathrm{CI}]=0.645$ to 0.717 ; Nagy et al. 1999). If there is an equitable distribution of resource use with respect to body size among species in avian communities, then the slope of the size-abundance relationship for birds should be in the range of -0.645 to -0.717 . Among birds in temperate communities, some sizeabundance relationships fit these expectations (table 1). Many slope estimates for birds, however, are shallower than -0.681 , and some are not significantly different from 0 (table 1). Birds in a Panamanian lowland forest have a shallow slope $(-0.25)$ that is significantly different neither from -0.681 nor from 0 (Brawn et al. 1995). Furthermore, some studies have found the shape of the scatterplot describing the relationship in temperate birds to reach a peak at intermediate body masses (Brown and Maurer 1987), rather than being linear and negative (Damuth 1981, 1987); this indicates that the most abundant avian species are of intermediate size.

Explanations for variation in the size-abundance relationship are related to energetics, scale of analysis, ecological factors, and evolutionary history (Lawton 1989; Blackburn et al. 1993b; Cotgreave 1993; Blackburn and Gaston 1997). This article focuses on ecological factors 
and evolutionary history, interpreting their effects in light of potential effects of scale. The ecological attributes of habitat structure and species membership in an ecological guild may affect size-abundance relationships. Habitats vary in resource availability and vegetation structure both temporally and spatially (Bell et al. 1991). If such variability affects avian species composition or population densities in different habitats, then variation in the slope of the size-abundance relationship among habitats may result. Size-abundance relationships also may differ among ecological guilds of birds (Peters and Wassenberg 1983; Juanes 1986). Among temperate birds, insectivore and carnivore guilds tend to have negative slopes, whereas herbivore and omnivore guilds tend to have slopes not significantly different from 0 , although this pattern is not consistent among studies (table 1). Nonetheless, having slopes not different from 0 in some guilds suggests that larger species may be more abundant than would be expected under the EER.

If variation in population density is constrained by body size via, for example, ecological or energetic mechanisms, then these traits should exhibit correlation across phylogenetic history. Most examinations of the size-abundance relationship have used statistical analysis of species values without incorporating either phylogenetic or taxonomic information, but more recent analyses have incorporated these sources of variation (Nee et al. 1991; Cotgreave and Harvey 1992, 1994; Blackburn et al. 1994; Cotgreave 1994, 1995; Gregory 1995). Comparative studies should incorporate phylogeny because trait values tend to be more similar among closely related species (Felsenstein 1985; Grafen 1989; Harvey and Pagel 1991). Although population density is often an ecologically labile trait, closely related species may share other traits that constrain population densities to be similar, and this has been shown to be the case for some avian life-history traits (Blackburn et al. 1996). Consequently, species values may not be independent of one another, which violates a fundamental assumption of most statistical tests. Nonindependence among data points can result in inflated test statistics and inappropriate conclusions concerning the nature of the relationship between the traits in question (Martins and Garland 1991; Harvey and Rambaut 1998; Garland and Ives 2000).

It has proven difficult to differentiate between the effects of evolutionary history and those of ecological similarity within guilds on the size-abundance relationship. In an analysis of British birds, the slopes of size-abundance relationships in higher taxonomic ranks were negative, whereas those in lower ranks were more likely to be positive (Nee et al. 1991). The authors suggested that phylogenetically distinct groups, that is, those with a long time since divergence from their most recent common ancestor, tend to form guilds in which interspecific competition may be intense. Within such groups, large body size may provide benefits in interspecific competitive interactions, especially if access to resources is determined by interference competition. The effects of interspecific competition on resource access may adversely affect the abundance of smaller species, which would explain slopes greater than or equal to 0 found in these groups. In contrast, analyses of wintering British, Irish, and resident Australian birds did not find any statistically significant tendency in the probability of obtaining a positive or a negative slope related to taxon rank (Blackburn et al. 1994; Cotgreave 1995). Nonetheless, in data from an Arizona experiment that manipulated levels of competition among birds, tribes that demonstrated strong interspecific competition were those in which the largest species were most abundant (Cotgreave 1994).

The Amazonian bird assemblage examined in our study has several characteristics that allow a unique contribution to our understanding of the relationship between size and abundance and the relationship's implications for patterns of PEU among species. First, to our knowledge, these analyses are the first exploration of this kind for a local, sympatric assemblage of tropical birds. Whether temperate and tropical birds differ in size-abundance relationships has been largely unexamined. This empirical gap may be important, given the potential for differences in metabolic rates between temperate and tropical taxa (Vleck and Vleck 1979; Hails 1983). Second, these data are from complete studies of the avian communities in three local rain forest habitats, censused using the same methods and often by the same observers (Terborgh et al. 1990; Robinson and Terborgh 1997; S. K. Robinson and J. Terborgh, unpublished data). Potential biases introduced from data compiled from literature sources using diverse methods in geographically distant communities are thereby reduced (Lawton 1989). In addition, examining whether the sizeabundance relationship might constrain community structure may be most appropriately done using a data set from a complete community study rather than data compiled from the literature (Blackburn et al. 1990; Pagel et al. 1991; Cotgreave and Harvey 1992). Third, this avian assemblage is very species rich, with more than 400 resident land birds, providing a large data set with which to examine sources of variation in the size-abundance relationship. Finally, the study site is pristine and has experienced little or no human development or exploitation, so that avian population densities should not be influenced by contemporary human impacts.

We addressed three questions. Does the slope of the logarithmic relationship between body mass and population density differ significantly from the slope of -0.681 expected under the EER? Does the slope of the logarithmic 
relationship between body mass and PEU differ significantly from the slope of 0 expected under the EER? Finally, do the slopes of the logarithmic relationships between body mass and abundance and between body mass and PEU vary among habitats or ecological guilds?

We tested for differences in the size-abundance relationship attributable to habitat using avian population densities in three habitats of increasing structural and floristic complexity: late successional forest, mature floodplain forest, and terra firme (upland) forest. We tested for differences in the size-abundance relationship among four trophic guilds: frugivore-omnivore, granivore, insectivore, and raptor. We analyzed species trait values without incorporating phylogenetic information, and we used a phylogenetic hypothesis to calculate independent contrasts (Felsenstein 1985; Harvey and Pagel 1991).

\section{Study Area and Methods}

Estimates of avian population densities were compiled from published and unpublished studies of avian community structure in floodplain and upland habitats in Manú National Park, Madre de Dios, southeastern Peru, within $5 \mathrm{~km}$ of the Cocha Cashu Biological Station $\left(11^{\circ} 54^{\prime} \mathrm{S}, 71^{\circ} 18^{\prime} \mathrm{W}\right.$, elevation approximately $400 \mathrm{~m}$; Terborgh et al. 1990; Robinson and Terborgh 1997; S. K. Robinson and J. Terborgh, unpublished data). The area lies near the climatic boundary between Tropical and Subtropical Moist Forest in the Holdridge system (Holdridge 1967).

All census plots, except the one in terra firme, were within the whitewater Manú River's 6-km-wide floodplain, which contains a complex mosaic of successional and mature forest stands that resulted from the meandering and flooding dynamics of the river (Terborgh and Petren 1991). The botanical characteristics and structure of the floodplain and upland habitats have been described in detail in previous publications (Foster 1990; Terborgh and Petren 1991; Robinson and Terborgh 1997). Briefly, as the Manú River meanders across its floodplain, it creates sand beaches along the point bar that are colonized by early successional vegetation. The early stages of this floodplain succession have species-poor bird communities and few coexisting syntopic congeners. Later successional stages in the floodplain consist of "transitional" forest, as the vegetation structure becomes more complex and the plant and bird communities more diverse, and some of the early successional species are lost. Mature floodplain forest, probably at least several hundred years old (Terborgh and Petren 1991), is floristically diverse and has a complex vertical structure. Of the four habitats in this study, mature floodplain forest contains the greatest numbers of bird species and coexisting congeners. Upland, or terra firme, is above the level of the floodplain and is dominated by very old, yet very heterogeneous forests.

Population densities (number of individuals per $100 \mathrm{ha}$ ) were estimated based on a combination of spot-mapping (Kendeigh 1944), mist-netting, transect, and breeding group census methods. Census methods are described in detail in Terborgh et al. (1990) and Robinson and Terborgh (1997) and are briefly summarized here. Census plot areas in each habitat were late successional forest, 60 ha; mature floodplain forest, $97 \mathrm{ha}$; and terra firme forest, 70 ha. Each plot was censused systematically for at least one season. Spot-mapping records were supplemented by mist-net captures, which helped to detect nonvocal species and also to provide color-banded individuals to help delineate territories of understory species. All records of each species were plotted on maps, and territorial boundaries were estimated and then used to obtain estimates of population density. For nonterritorial species, we estimated population density by counting males at leks (manakins and cotingas) or by recording the maximum number of individuals observed at fruiting trees. Territory size estimates were based on an average of 15-30 registrations per pair. The variety of census methods used and the use of spot mapping minimized any potential bias in population density estimates that might result from using only song census methods (see Calder 2000). Species for which our census methods would have produced a biased population density estimate (Apodidae, Trochilidae, Chloroceryle inda, Chloroceryle aenea, Piculus leucolaemus, Piculus chrysochloros, Cacicus cela, Psarocolius oseryi, Psarocolius decumanus, Psarocolius angustifrons, and Psarocolius yuracares) were excluded from the data set. Although swifts (Apodidae) and hummingbirds (Trochilidae) are some of the smallest species in this community, the available estimates of population densities for these species span a range from rare to abundant (Terborgh et al. 1990); this makes any bias resulting from their exclusion from the analysis unlikely. Migratory species also were excluded (Chordeiles minor, Chordeiles rupestris, Coccyzus americanus, Coccyzus melacoryphus, Contopus borealis, Contopus virens, Vireo olivaceous). Body masses (in grams) were field measurements from birds measured at the four census plots or from museum specimens collected elsewhere in southeastern Peru or Bolivia (Louisiana State University Museum of Natural History, Field Museum of Natural History).

Population energy use (kJ per species per day per 100 ha) was calculated as the product of individual metabolic rate (kJ per individual per day) and population density (Taper and Marquet 1996). Ideally, calculation of PEU in this study should use species- or genus-specific estimates of FMR for tropical birds. Unfortunately, such data are not available. Feeding guild may be an important source of interspecific variation in metabolic rate (McNab 1988), 
although analyses using methods that incorporate phylogenetic information have failed to find differences among guilds (Bennet and Harvey 1987). Interspecific studies of metabolic rate have also shown that tropical bird species, particularly frugivores, may have reduced metabolic rates, relative to birds from higher latitudes (Weathers 1979, 1997; Bartholomew et al. 1983; Hails 1983). However, substantial within-family variation exists in whether tropical species' metabolic rates are higher or lower than would be predicted based on temperate species (Vleck and Vleck 1979; Schleucher 1999; McNab 2001). We therefore consider the available literature to be inadequate to provide detailed taxon- or guild-specific estimates of FMR for use in this study. Although early studies indicated that metabolic rates differed between passerine and nonpasserine birds (Lasiewski and Dawson 1967; Bennet and Harvey 1987), a recent analysis that incorporates phylogenetic information found no differences in metabolic rate between passerines and nonpasserines (Reynolds and Lee 1996). For these reasons, we elected to calculate PEU using the allometric relationship for FMR for all birds presented in Nagy (1999). Some studies suggest that frugivorous species may have lower metabolic rates than species of other feeding guilds (McNab 1986, 1988, 2001). To account for this potential source of variation, we also conducted PEU analyses with an individual metabolic rate that was reduced by $75 \%$ ( $\mathrm{McNab} 2001)$ for all species in the frugivore-omnivore guild. Neither the slope nor the significance of the overall relationship or of each guild was significantly affected by this adjustment.

The four guilds were broadly defined, given that most species' diets are not known in detail (Remsen et al. 1993). In general, diets of species considered frugivore-omnivores contain mostly fruit, supplemented by insects, nectar, small vertebrates, or seeds. Granivores, insectivores, and raptors consume primarily seeds, insects, and vertebrates, respectively, although species in these guilds may supplement their diets to an unknown and presumably small extent with other food items.

\section{Statistical Analysis}

Using the mixed procedure in SAS (SAS Institute 2000), we modeled the relationship between body mass, population density, habitat (late successional, mature floodplain, and terra firme forests), and ecological guild (frugivore-omnivore, granivore, insectivore, and raptor) using species trait values. For all analyses, body mass and population density were logarithmically transformed. Because many species occurred in more than one habitat and therefore were represented more than once in the data set, random effects were included in the model by treating species as nested within guild. We tested for significant variation in the slope (interaction terms) and in the least squares means (main effects) attributable to habitat and guild. Least squares means reflect the variation in average avian population density. In the full model with all main effects and interactions, neither the main effect of habitat nor the interactions between habitat and body mass and between habitat and guild explained a significant amount of the variation in population density (table 2). These results indicate that average mean avian population density, the slope of the size-abundance relationship, and population densities of species in each guild, respectively, did not vary significantly among habitats. These terms were therefore pooled into error for all subsequent analyses. In all subsequent analyses, we used a logarithmic transformation of either mean population density for species occurring in more than one habitat or the observed population density for species occurring in only one habitat as the dependent variable in size-abundance analyses and PEU calculations. Each species, therefore, was represented by only one point in the data set, which allowed results based on species values to be compared directly with those based on phylogenetically independent contrasts.

We also tested whether the relationships of population density and PEU to body mass, using species values and phylogenetically independent contrasts, would best be modeled using a single error variance for all guilds or separate error variances for each guild. Unequal variances among guilds would affect the comparisons of slopes among guilds. In all cases, comparisons of the scores of the Akaike Information Criterion for the two models using the mixed procedure in SAS indicated that the model using a single variance for all guilds was the best model (Burnham and Anderson 1998). We therefore used the standard output of the mixed procedure for comparisons of slopes among guilds, and we adjusted for multiple comparisons using Tukey's HSD method (Zar 1996) with an experiment-wise error rate of $P<0.05$.

The choice of an appropriate regression model to use in allometric analyses is a complicated issue (Rayner 1985; McArdle 1988). In our study, as in most allometric analyses, the independent variable (body mass) cannot be as-

Table 2: Mixed model statistics for the relationship between body mass and population density for birds in three Neotropical rain forest habitats and four ecological guilds

\begin{tabular}{lrrc}
\hline Fixed effect & $\mathrm{df}$ & $F$ value & Probability \\
\hline Log(body mass) & 1,293 & 11.19 & .0009 \\
Guild & 3,265 & 3.00 & .0312 \\
Habitat & 2,339 & .07 & .9315 \\
Guild $\times$ habitat & 6,355 & .56 & .7616 \\
Log(body mass) $\times$ guild & 3,265 & 3.39 & .0185 \\
$\log ($ body mass $) \times$ habitat & 2,334 & .54 & .5831 \\
\hline
\end{tabular}


sumed to be measured without error, which is an assumption of ordinary least squares (OLS) regression. The general structural relation (GSR) may be employed to account for the error variances in the dependent and independent variables if these quantities are known (Rayner 1985). As is often the case in analyses of size-abundance relationships, our data do not contain information on the error variance in population density, making it impossible to use the GSR. In such cases, some workers have advocated use of reduced major axis (RMA) regression (e.g., Griffiths 1998), although others discourage its use (Harvey and Pagel 1991).

The fact that the predictor variable is subject to error is not the only criterion for selecting RMA regression. The RMA method assumes that the ratio between the error variances in the dependent and independent variables is equal to that of the variances in these variables (Rayner 1985; McArdle 1988). This assumption, however, is unlikely to be true for our population density and body mass data. This is because the error variance in body mass is a very small proportion of the variance in body mass, whereas the error variance in population density is likely to be a relatively much greater proportion of the variance in population density. The slope estimate provided by OLS regression has little or no bias when the error variance is substantially smaller than the variance of the independent variable (Madansky 1959; Draper and Smith 1998). When the independent variable is subject to error, the slope estimated by OLS regression should be multiplied by the term $\left[1+\left(\sigma_{u}^{2} / \sigma_{X}^{2}\right)\right]$, where $\sigma_{u}^{2}$ is the error variance and $\sigma_{X}^{2}$ is the variance in the independent variable (Madansky 1959; Draper and Smith 1998). Using measurements of body masses of multiple individuals of each species to calculate $\sigma_{u}^{2}$, we used this equation to estimate that error in body mass measurement results in a $0.5 \%$ shallower slope than would be estimated if body mass were measured without error. This small degree of bias is unlikely to affect our conclusions. We therefore used OLS regression in all analyses because the assumptions of this model better fit our data than do those of RMA regression. As an additional verification of the validity of OLS regression, an orthogonal quantile regression method was used to calculate the slope of the relationship between population density and body mass. This method yields estimates that converge strongly to the true values of parameters when there is error in the predictor variable (He and Liang 2000).

Phylogenetically independent contrasts, as implemented in the computer program CAIC (Purvis and Rambaut 1995), were used to examine the relationship between body mass and population density and between body mass and PEU for all species combined and for species in each of the four ecological guilds individually. Although an ideal comparative test would use a complete phylogeny of Neo- tropical bird species, such a phylogeny is not available. We therefore constructed a phylogeny that included all species represented in our data set, based on phylogenetic hypotheses for these taxa published in the literature cited in the appendix. We used the phylogenetic hypothesis of Sibley and Ahlquist (1990) to represent the backbone of the tree (lower nodes) because their phylogeny achieves the most complete taxon sampling at lower taxonomic levels. For higher taxonomic levels, we used clade-specific, published phylogenetic hypotheses (appendix) for taxa not represented in Sibley and Ahlquist (1990) or when taxon sampling of a clade was more complete than that in Sibley and Ahlquist (1990). Taxa for which no information on phylogenetic relationships was available were placed in the tree assuming sister taxon relationships according to the taxonomy of Sibley and Monroe (1990).

Because the final phylogenetic tree was a composite from multiple sources, branch lengths could not be estimated. We therefore tested whether appropriately standardized contrasts could be obtained by using uniform branch lengths or by using branch lengths assigned with the assumption that the ages of taxa are proportional to the number of species they contain (Grafen's branch lengths; Grafen 1989; Purvis and Rambaut 1995). We examined the correlation between the absolute values of the standardized contrasts and their standard deviations to ensure that branch lengths were appropriately scaled (Garland et al. 1992; Diaz-Uriarte and Garland 1996). Using Grafen's branch lengths resulted in substantially more assumption violations. Using uniform branch lengths, in all but five of 15 cases, there was no statistically significant relationship between these variables. Comparative analyses using the method of phylogenetically independent contrasts should use appropriately standardized contrasts (Garland et al. 1992); however, limitations to options for standardizing contrasts arise when branch lengths cannot be estimated from the phylogeny, as is the case here. Simulations have shown that phylogenetically based statistical methods generally perform better than nonphylogenetic ones, even under deviations from the Brownian motion model, which occurs when contrasts are not properly standardized (Diaz-Uriarte and Garland 1996). Therefore, all contrasts were calculated using uniform branch lengths because this method allowed standardization of most but not all contrast variables. Regressions involving contrasts that did not appear to be standardized properly are indicated in tables 3 and 4 . For the five cases with a statistically significant correlation between the absolute values of the standardized contrasts and their standard deviations, the Pearson correlation coefficients were relatively low $(-0.18$ to -0.35$)$, and inspection of the scatterplot did not reveal a strong relationship. Nonetheless, for regressions involving potentially improperly standardized con- 
Table 3: Ordinary least squares regression statistics for the relationship between population density and body mass based on nonphylogenetic (species) and phylogenetic (contrasts) analyses of all data and data grouped by guild

\begin{tabular}{|c|c|c|c|c|c|c|}
\hline & $n$ & Slope (SE) & $95 \% \mathrm{CI}$ & $\begin{array}{l}\text { Probability } \\
(\text { slope }=0)\end{array}$ & $\begin{array}{c}\text { Correlation } \\
\text { coefficient }\end{array}$ & $\begin{array}{c}\text { Probability } \\
(\text { slope }=-.681)\end{array}$ \\
\hline \multicolumn{7}{|l|}{ Nonphylogenetic: } \\
\hline All data $\left(R^{2}=.08\right)$ & 272 & $-.22(.04)$ & $(-.31,-.13)$ & .0001 & $-.29^{\mathrm{a}}$ & .0005 \\
\hline \multicolumn{7}{|l|}{ Ecological guild: } \\
\hline Frugivore-omnivore & 69 & $.03(.09)^{\mathrm{A}}$ & $(-.14, .21)$ & .7098 & .05 & .0005 \\
\hline Granivore & 24 & $-.30(.15)^{\mathrm{A}, \mathrm{B}}$ & $(-.62, .02)$ & .0514 & -.38 & .025 \\
\hline Insectivore & 160 & $-.32(.08)^{\mathrm{B}}$ & $(-.49,-.16)$ & .0001 & $-.30^{\mathrm{a}}$ & .0005 \\
\hline Raptor & 19 & $-.58(.26)^{\mathrm{A}, \mathrm{B}}$ & $(-1.13,-.04)$ & .0200 & $-.46^{\mathrm{a}}$ & $>.05$ \\
\hline \multicolumn{7}{|l|}{ Phylogenetic: } \\
\hline All data $\left(R^{2}=.02\right)$ & 204 & $-.18(.09)$ & $(-.36,-.02)$ & .047 & $-.14^{\mathrm{a}}$ & .0005 \\
\hline \multicolumn{7}{|l|}{ Ecological guild: } \\
\hline Frugivore-omnivore & 55 & $-.07(.16)^{\mathrm{A}}$ & $(-.38, .24)$ & $.657^{\mathrm{b}}$ & -.06 & .025 \\
\hline Granivore & 15 & $-.45(.21)^{\mathrm{A}}$ & $(-.91, .01)$ & .054 & -.49 & $>.05$ \\
\hline Insectivore & 115 & $-.22(.14)^{\mathrm{A}}$ & $(-.51, .06)$ & $.126^{\mathrm{b}}$ & -.14 & .025 \\
\hline Raptor & 18 & $-.31(.21)^{\mathrm{A}}$ & $(-.76, .14)$ & .166 & -.33 & $>.05$ \\
\hline
\end{tabular}

Note: The standard error (SE) and 95\% confidence interval (95\% CI) of each slope are given. Differences in slopes among guilds are indicated next to the parameter estimate for each guild, based on planned comparisons using Tukey's HSD method with an experimentwise error rate of $P<.05$.

a Statistically significant Pearson's correlation coefficient. For phylogenetic analyses, these correlations were forced through the origin.

${ }^{b}$ Regressions involving independent contrasts that could not be appropriately standardized. These relationships also were examined using sign tests. The sign test was consistent with the regression for the frugivore-omnivore guild but suggested a statistically significant negative relationship for the insectivore guild.

trasts, we also performed sign tests to evaluate the validity of these regressions (tables 3,4 ).

Whether the shape of the scatterplot of the relationship between population density and body mass is influenced by evolutionary constraints was investigated using two methods to estimate the upper bound slope (UBS): quantile regression on species values (Scharf et al. 1998; Cade et al. 1999; Buchinsky 2001) and a method developed by Blackburn et al. (1992). If constraints on the shape of the scatterplot were consistent with the EER, then the UBS of the scatterplot would be expected to approach -0.681 . The UBS was estimated using quantile regression on the $90 \%$ quantile of population density (Scharf et al. 1998). Using the method of Blackburn et al. (1992), the body mass data were divided into 17 size classes, with no size class having fewer than three species (data points). The species with the highest population density in each size class was selected, for a total of 17 points in the UBS regression analysis.

Student's $t$-test (Sokal and Rohlf 1995) was used to test whether slopes were different from a slope of -0.681 expected under the EER. Throughout this article, significance is assessed at the $P<.05$ level.

\section{Results}

\section{Nonphylogenetic Regression (Species Analysis)}

Based on species values, the overall negative relationship between body mass and population density was statistically significant, but body mass explained only a small proportion of the variation in population density $(F=$ 24.52, $\mathrm{df}=1,270, P<.0001, R^{2}=0.08$; fig. $\left.1 \mathrm{~A}\right)$. The slope of the regression was significantly greater than -0.681 (one-tailed; $t=11.525$, df $=270, P<.0005$; table $3)$. The slope estimate using orthogonal quantile regression was -0.27 (95\% CI: $-0.36,-0.18)$. These confidence intervals include the OLS slope estimate of -0.22 . The estimate of the UBS using the $90 \%$ quantile was not significantly different from $0(b=-0.07 ; 95 \%$ CI: -0.23 , 0.08 ), and the estimate that used the method of Blackburn et al. (1992) was -0.18 ( $P=.017$; 95\% CI: $-0.04,-0.32)$. Average population densities differed among guilds (least squares means; $F=3.49, \mathrm{df}=3,264, P=.0163$ ), with granivores having a significantly higher average population density than insectivores $(P=.0489)$.

Variation in the slope of the size-abundance relationship attributable to guild was significant $(F=3.91, \mathrm{df}=$ $3,264, P=.0093$; fig. 2). Only slopes for insectivore and raptor guilds were significantly different from 0 (table 3 ). The slopes of all guilds except raptors were significantly shallower than -0.681 (table 3 ). The slope of the frugivore-omnivore guild differed significantly from those of insectivores $(P=.0036)$ and raptors $(P=.0262)$, but no other among-guild comparisons were significantly different (table 3). Only the difference between frugivoreomnivore and insectivore guilds remained statistically significant (experiment-wise $P<.05$ ) after adjusting for 
Table 4: Ordinary least squares regression statistics for the relationship between population energy use and body mass based on nonphylogenetic (species) and phylogenetic (contrasts) analyses of all data and data grouped by guild

\begin{tabular}{|c|c|c|c|c|c|}
\hline & $n$ & Slope (SE) & $95 \% \mathrm{CI}$ & $\begin{array}{l}\text { Probability } \\
(\text { slope }=0)\end{array}$ & $\begin{array}{c}\text { Correlation } \\
\text { coefficient }\end{array}$ \\
\hline \multicolumn{6}{|l|}{ Nonphylogenetic: } \\
\hline All data $\left(R^{2}=.29\right)$ & 272 & $.46(0.08)$ & $(.33, .55)$ & .0005 & $.54^{\mathrm{a}}$ \\
\hline \multicolumn{6}{|l|}{ Ecological guild: } \\
\hline Frugivore-omnivore & 69 & $.71(.09)^{\mathrm{A}}$ & $(.54, .89)$ & .0005 & $.70^{\mathrm{a}}$ \\
\hline Granivore & 24 & $.38(.15)^{\mathrm{A}, \mathrm{B}}$ & $(.06, .70)$ & .0137 & $.46^{\mathrm{a}}$ \\
\hline Insectivore & 160 & $.36(.08)^{\mathrm{B}}$ & $(.19, .52)$ & .0005 & $.33^{\mathrm{a}}$ \\
\hline Raptor & 19 & $.10(.26)^{\mathrm{A}, \mathrm{B}}$ & $(-.45, .65)$ & .7054 & .09 \\
\hline \multicolumn{6}{|l|}{ Phylogenetic: } \\
\hline All data $\left(R^{2}=.12\right)$ & 204 & $.49(.09)$ & $(.26, .62)$ & $.0001^{\mathrm{b}}$ & $.34^{\mathrm{a}}$ \\
\hline \multicolumn{6}{|l|}{ Ecological guild: } \\
\hline Frugivore-omnivore & 55 & $.56(.16)^{\mathrm{A}}$ & $(.24, .88)$ & $.0009^{\mathrm{b}}$ & $.44^{\mathrm{a}}$ \\
\hline Granivore & 15 & $.23(.21)^{\mathrm{A}}$ & $(-.22, .70)$ & .2922 & .28 \\
\hline Insectivore & 115 & $.46(.14)^{\mathrm{A}}$ & $(.18, .74)$ & $.0018^{\mathrm{b}}$ & $.28^{\mathrm{a}}$ \\
\hline Raptor & 18 & $.37(.21)^{\mathrm{A}}$ & $(-.08, .82)$ & .0996 & .39 \\
\hline
\end{tabular}

Note: The standard error (SE) and 95\% confidence interval (95\% CI) of each slope are given. Differences in slopes among guilds are indicated next to the parameter estimate for each guild, based on planned comparisons using Tukey's HSD method with an experiment-wise error rate of $P<.05$.

a Statistically significant Pearson's correlation coefficients; for phylogenetic analyses, these correlations were forced through the origin.

b Regressions involving independent contrasts that could not be appropriately standardized. These relationships also were examined using sign tests. The sign test was consistent with the regression for all cases except the frugivore-omnivore guild, which suggested a marginally nonsignificant $(P=.052)$ positive relationship.

multiple comparisons. Although the difference between the slopes for the frugivore-omnivore and raptor guilds was not statistically significant after adjusting for multiple comparisons (frugivore-omnivore vs. raptor guilds: $t=$ 2.24 , critical $q=2.57$ ), the magnitude of the difference between the slope estimates suggests that the difference is biologically significant. However, the test may have lacked power to detect a difference due to the high standard error of the slope estimate and the low sample size for the raptor guild.

The relationship between PEU and body mass also was statistically significant $(F=108.69, \mathrm{df}=1,270, P<.001$, $R^{2}=0.29$; fig. $3 A$ ), with a slope significantly greater than 0 (one-tailed; $t=10.43, \mathrm{df}=270, P<.0001$; table 4). Variation attributable to guild was significant $(F=3.91$, $\mathrm{df}=3,264, P=.0093)$. Only the slope for the raptor guild was not different from 0 ; slopes for all other guilds were significantly positive (table 4). Differences among guilds in the slope of the body size-PEU relationship paralleled those for the size-abundance relationship (table 4).

\section{Independent Contrasts Analyses}

The regression of phylogenetically independent contrasts of population density and body mass was statistically sig- nificant $\left(F=3.98, \mathrm{df}=1,203, P=.047, R^{2}=0.02\right.$; fig. $1 B$ ), but again, body mass explained little of the variation in population density. The negative slope also was significantly different from 0 (one-tailed; $t=-1.994, \mathrm{df}=$ 202, $P=.047$; table 3 ) and was significantly shallower than -0.681 (one-tailed; $t=5.57, \mathrm{df}=202, P<.0005$; table 3). Slopes of guilds did not differ significantly (table 3 ). None of the slopes for guilds differed significantly from 0 , although the slopes for frugivore-omnivores and insectivores both differed significantly from -0.681 (table 3 ).

Based on independent contrasts, the relationship between PEU and body mass was statistically significant $\left(F=28.33, \mathrm{df}=1,203, P<.0001, R^{2}=0.12\right.$; fig. $\left.3 B\right)$, with a slope significantly greater than 0 (one-tailed; $t=$ 5.322, $\mathrm{df}=202, P<.001$; table 4 ). Slopes of guilds did not differ significantly (table 4). The slopes for the raptor and granivore guilds were not different from 0 ; slopes for all other guilds were significantly positive (table 4 ).

\section{Discussion}

\section{Sources of Variation}

Nonphylogenetic (species) and phylogenetic (contrasts) analyses of the size-abundance relationship for Amazonian birds in this community gave similar results. Both regres- 

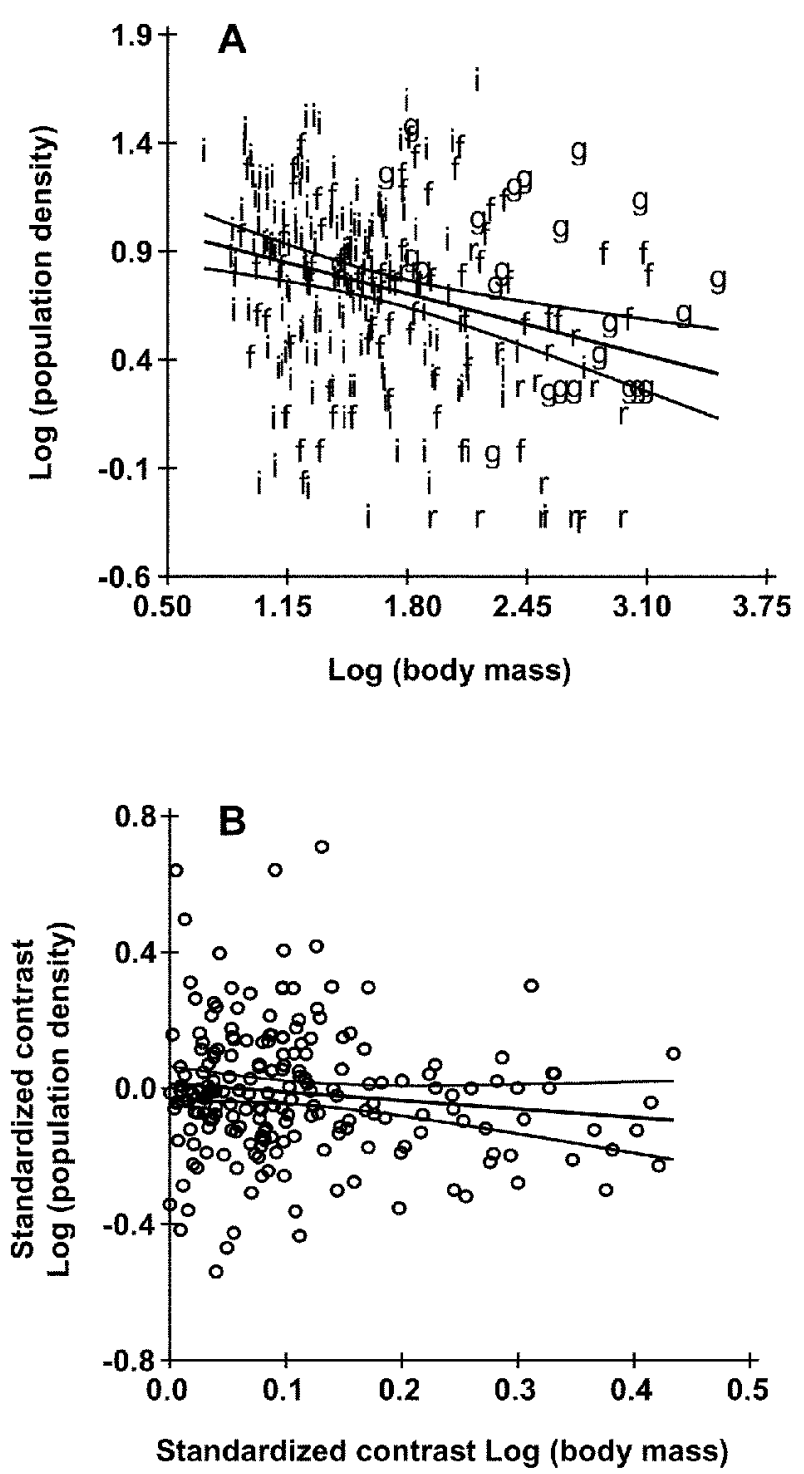

Figure 1: $A$, Scatterplot of species values of population density versus body mass. Ordinary least squares regression line and $95 \%$ confidence intervals of the slope are depicted. Letters represent guild designation of each point: $f$, frugivore-omnivore; $g$, granivore; $i$, insectivore; $r$, raptor. $B$, Scatterplot of phylogenetically independent contrasts of population density versus body mass. Ordinary least squares regression line and 95\% confidence intervals of the slope are depicted. Note difference in scales.

sions were statistically significant, with similar slopes that were significantly shallower than the slope of -0.681 , which would be the slope expected if the EER applied in this bird community (table 3 ). That the size-abundance relationship retained statistical significance after accounting for phylogeny suggests that these two traits are likely to have undergone some form of correlated evolution (Fel- senstein 1985; Harvey and Pagel 1991). Nonetheless, the low coefficients of determination indicate that many unaccounted-for sources of variation affect the sizeabundance relationship for Amazonian birds in this community. Our analysis is consistent with several studies that conclude that the relationship between body mass and population density can be highly variable (e.g., Pagel et al. 1991; Blackburn et al. 1993b; Brawn et al. 1995; Blackburn and Gaston 1997). Rather than simple regressions, analyses investigating the sources of variation in the relationship, such as the ecological and phylogenetic attributes addressed in this study, may be more informative.

The resource availability in and vegetation structure of successional habitats are often temporally and spatially more variable than those in mature forest understory (Frankie et al. 1974; Croat 1975; Stiles 1975; Opler et al. 1980). If such variability affects avian taxonomic composition or population densities of early successional versus mature forests, differences in the slope of the sizeabundance relationship among habitats may result. Our finding of no difference in slopes among the three habitats, based on nonphylogenetic analyses (see "Study Area and Methods"; table 2), contrasts with previous studies that found that the slope of the size-abundance relationship for birds had a significantly negative correlation with a foliage volume index (Tellería and Carrascál 1994).

Based on nonphylogenetic analyses, guilds differed in the slope of the size-abundance relationship (tables 2, 3). The slopes of all guilds except for raptors were significantly different from the -0.681 slope expected under the EER (table 3). Relative to the raptor guild, the slopes for the other three guilds were much shallower, suggesting that larger species in frugivore-omnivore, granivore, and insectivore guilds are more abundant than would be predicted based on energetics. These results would not be expected if the EER were a significant factor affecting population densities in these guilds. The significant influence of guild on the size-abundance relationship is also consistent with findings that foraging guild is a significant source of variation in demographic traits of Panamanian forest birds (Brawn et al. 1995).

Phylogenetic analyses indicated no statistically significant differences among guilds in the slope of the sizeabundance relationship (table 3 ). One possible explanation for this result is that evolutionary relationships and feeding guild may be correlated to an extent that varies among guilds. For example, all raptor species are represented in two clades, and the majority of insectivores are represented in three clades. Thus, controlling for the effects of phylogeny may remove from the analysis some variation attributable to feeding guild. Some similarities, however, existed between the two analyses. In the phylogenetic analysis, slopes of the frugivore-omnivore and insectivore 


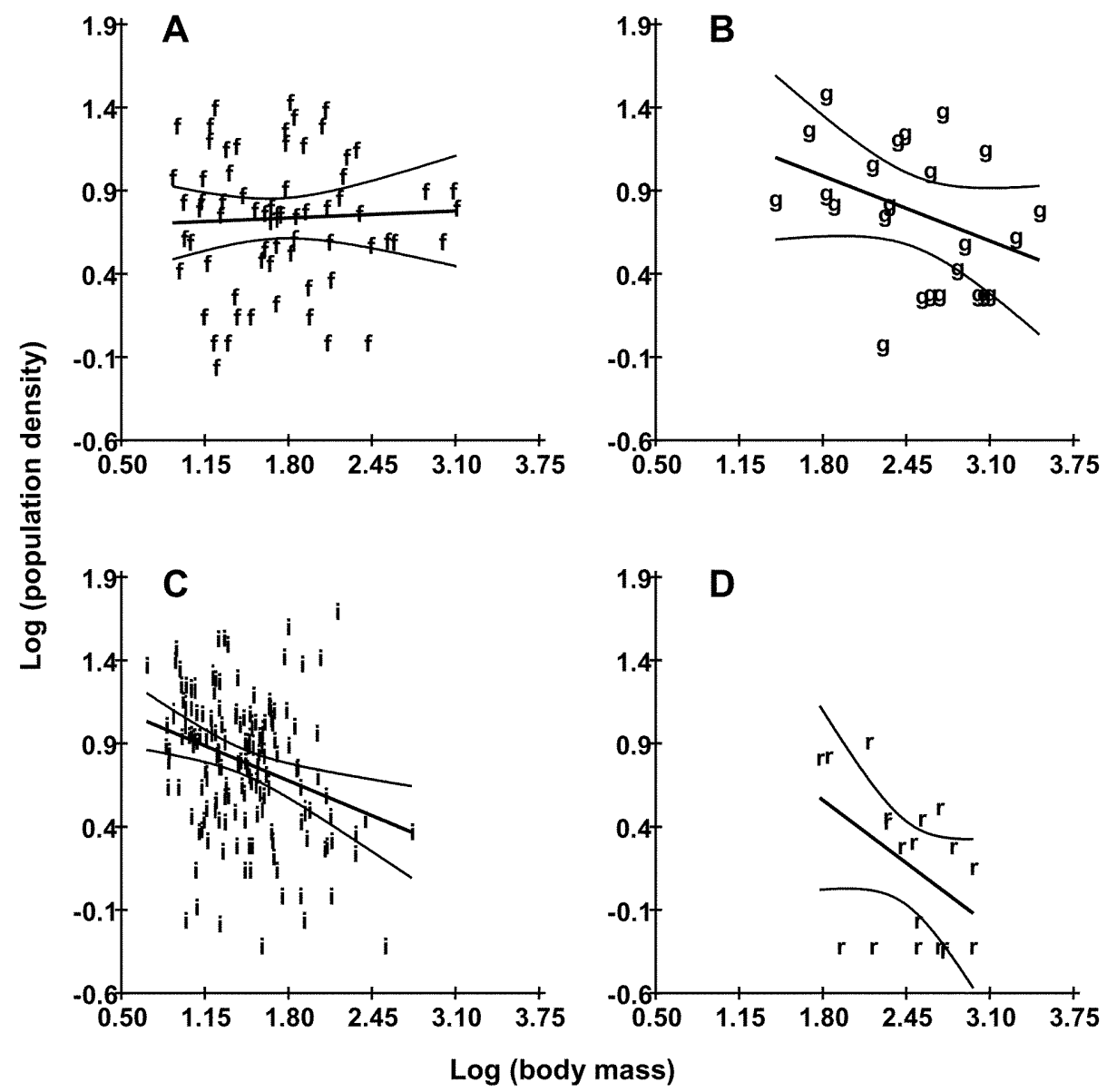

Figure 2: Scatterplots of species values of population density versus body mass grouped by guild. Ordinary least squares with least squares regression line and $95 \%$ confidence intervals of the slope are depicted. Letters represent guild designation of each point: $f$, frugivore-omnivore; $g$, granivore; $i$, insectivore; $r$, raptor. $A$, Frugivore-omnivore guild; $B$, granivore guild; $C$, insectivore guild; $D$, raptor guild.

guilds were significantly shallower than -0.681 , whereas those for raptors were not, and this is consistent with the nonphylogenetic analysis. These results would not be expected if the EER were a significant factor affecting population densities in these guilds.

Both nonphylogenetic and phylogenetic analyses of the relationship between PEU and body mass produced statistically significant, positive slopes that were similar to each other (table 4). To the extent that variance in PEU is reflected in variance in species abundance patterns (Taper and Marquet 1996), our findings do not support the EER. Although the scatter around the regression line is considerable, our results strongly suggest that in this Amazonian bird community species having larger body masses tend to consume more energetic resources than do species having smaller body masses. Furthermore, both nonphylogenetic and phylogenetic analyses suggest that larger species' dominance of resource use within guilds is strongest in frugivore-omnivore, granivore, and insectivore guilds (fig. $3 A$; table 4).

\section{Hypotheses Explaining Variation among Guilds}

In this Amazonian bird community, we found that frugivore-omnivores, granivores, and insectivores had more positive slopes of the size-abundance relationship than did raptors and that populations of larger species tended to use more resources than those of smaller species, especially in the frugivore-omnivore guild. The hypothesis that competitive dominance of shared resources by larger species, either now or in the evolutionary past, may adversely affect the population densities of smaller species has been suggested to explain the lack of negative sizeabundance slopes observed in some guilds (Brown and Maurer 1986; Nee et al. 1991; Pagel et al. 1991; Cotgreave and Harvey 1992, 1994; Cotgreave 1994, 1995). The effect 

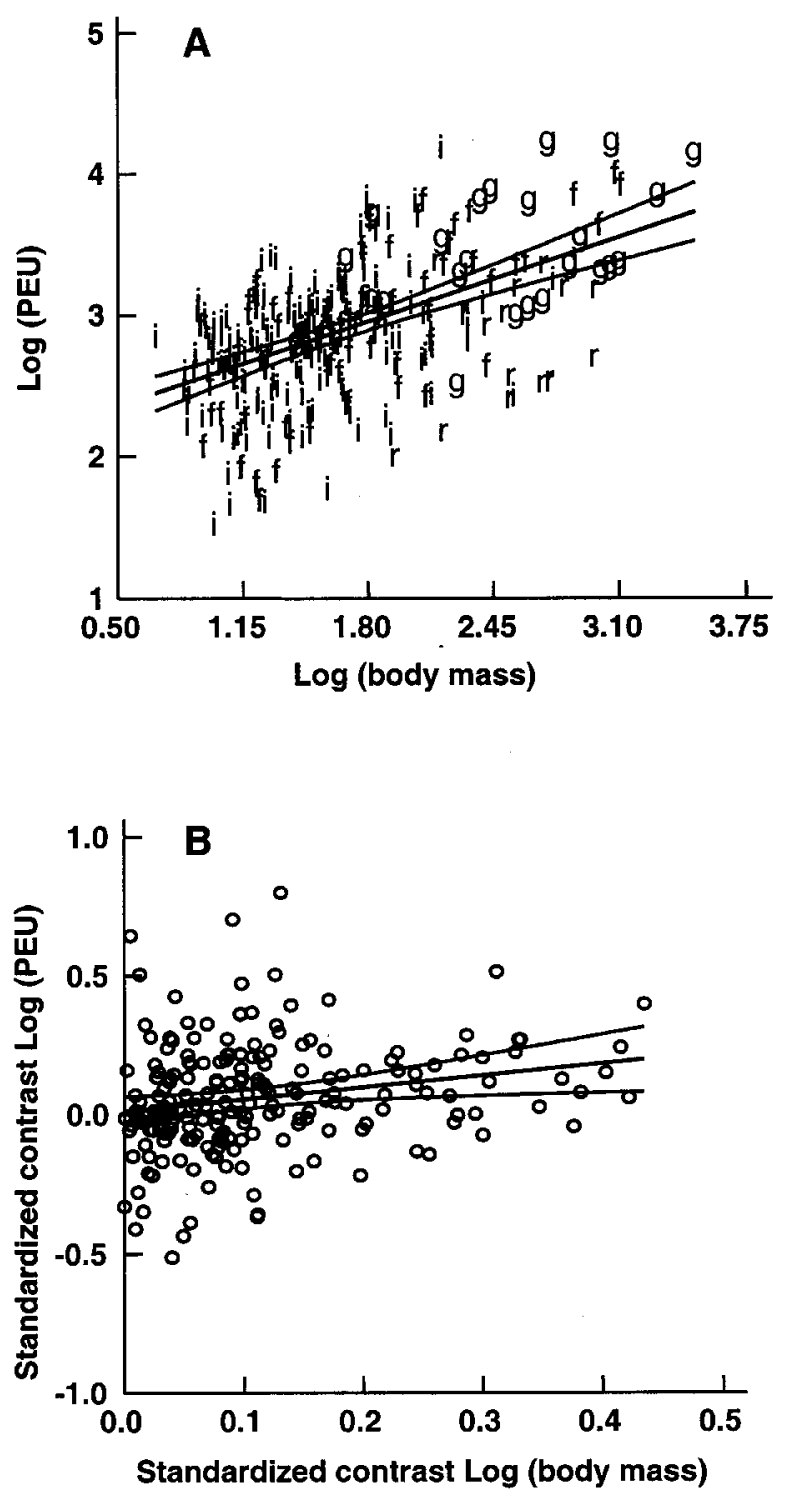

Figure 3: $A$, Scatterplot of species values of population energy use (PEU) versus body mass. Ordinary least squares regression line and 95\% confidence intervals of the slope are depicted. Letters represent guild designation of each point: $f$, frugivore-omnivore; $g$, granivore; $i$, insectivore; $r$, raptor. $B$, Scatterplot of phylogenetically independent contrasts of PEU versus body mass. Ordinary least squares regression line and 95\% confidence intervals of the slope are depicted. Note difference in scales.

of competitive dominance by larger species may be especially prominent in monophyletic groups that comprise complete guilds, which are more likely to have positive size-abundance relationships, and this suggests that phylogenetic and ecological divergence may be closely linked (Nee et al. 1991). When we controlled for phylogeny, differences in slopes among guilds were not found, lending support to this hypothesis.
Large body size can provide advantages in interspecific interactions involving either interference or exploitation competition, especially when resources are spatially clumped (Maurer 1984; Petren and Case 1996). For example, competitive dominance by a gecko of larger body mass (Hemidactylus frenatus) over one of smaller body mass (Lepidodactylus lugubris) occurs only when their insect prey is artificially concentrated into dense patches in the presence of light (Petren et al. 1993; Case et al. 1994). We found that the frugivore-omnivore guild showed the strongest deviations from the predictions of the EER. The food resources of frugivores are distributed in perhaps the most concentrated patches, relative to those of the other guilds examined here. Frequently observed interspecific aggression, agonistic displays, and displacements at fruiting trees (Howe 1977; Pratt 1984; Santana and Milligan 1984; Gautier-Hion and Michaloud 1989; Greenberg et al. 1993; Daily and Ehrlich 1994) suggest that interference competition may affect the foraging efficiency of frugivores. Interspecific dominance hierarchies consistent with body size have been observed among frugivores at fruiting trees in Costa Rica (Daily and Ehrlich 1994) and among frugivorous African hornbills (Leighton 1982; A. French, personal communication). The hypothesis that the benefits of large body size in competition are responsible for shallow slopes of the size-abundance relationship and the positive slope of the size-PEU relationship within guilds has received considerable support in analyses of sizeabundance relationships (Nee et al. 1991; Cotgreave 1994, 1995; Cotgreave and Harvey 1994). Costs of interspecific competition have been documented (Abramsky et al. 2000, 2001), but ultimately, evidence for a population-level effect, in terms of reduced demographic parameters such as survival or fecundity of small, relative to large, competing species, would be most convincing.

The slope of the size-abundance relationship for the insectivore and granivore guilds, while not as shallow as that for the frugivore-omnivore guild, is still significantly shallower than that expected under the EER. The PEU is also greater for insectivorous and granivorous species of larger, relative to smaller, body size. Interference competition involving territoriality among insectivore species may contribute to these patterns. At our study site, many insectivorous congeneric species pairs maintain interspecific territories, and heterospecific song playback experiments showed dominance by the larger congener (Robinson and Terborgh 1995). If larger congeners are able to force smaller congeners to occupy territories in poorerquality habitats, then the larger congeners may be able to maintain relatively larger population densities. The sizeabundance relationship for insectivores in Amazonian forests may also be affected by constraints imposed by membership in understory and canopy mixed-species flocks 
(Munn and Terborgh 1979; Munn 1985). Species participating in mixed-species flocks defend common territory boundaries through intraspecific aggression, causing a limit of one family group per species. The effect is to impose an equitable distribution of population densities for flocking species that is independent of body mass (Powell 1979).

Because we examined the effect of guild on the sizeabundance relationship, we have focused our discussion on how interspecific competition for dietary resources may affect population densities of large and small species. However, interspecific competition for other limited resources such as nest sites may also influence the relative population densities of large and small species if larger species have a competitive advantage. Other hypotheses have been suggested to explain why larger species might use more resources than smaller ones (Maurer and Brown 1988; Pagel et al. 1991). One important alternative explanation for this Amazonian bird community is that larger frugivores may be more energetically efficient than their smaller counterparts because organisms with larger bodies tend to be better at processing poor-quality abundant foods such as fruit (Case 1979).

Population densities are also likely to be limited by other factors in addition to the intrinsic metabolic properties of species. For example, population densities of mammalian carnivores have been found to be significantly constrained by both metabolic rates and prey abundance (Carbone and Gittleman 2002). Large frugivorous birds eat both small and large fruits, whereas small frugivores can eat only small fruits (Wheelwright 1985). Population densities of larger frugivores may therefore be less likely to be resource limited, relative to those of smaller frugivores, and this might allow them to achieve higher population densities than would be predicted based on energetics. The patchy distribution of fruit resources may release larger frugivores from resource limitation to a greater extent than larger representatives of other guilds.

\section{Temperate-Tropical Comparisons and the Effect of Scale}

The slope and coefficient of determination for sizeabundance relationships of the bird community in these Amazonian forests are in the low end of the range documented for regional and global studies of temperate birds (table 1); however, this comparison is complicated by the different scales of analysis. The majority of analyses of sizeabundance relationships and the EER have involved temperate taxa and regional or global data sets, and the EER was originally formulated with such a data set (Damuth 1981, 1987). Substantial evidence in animals, however, suggests that different patterns tend to arise at different scales of analysis (Gaston and Blackburn 1996; Blackburn and Gaston 1997). As we have found, the strength of these relationships tends to be weaker and to deviate from the expectations of the EER in community-level analyses relative to analyses at larger scales (Blackburn et al. 1990; Currie 1993; Blackburn and Gaston 1997).

We found the shape of the scatterplot not to be linear and negative, as was Damuth's $(1981,1987)$. Furthermore, the estimates of the UBS, using quantile regression on the 90\% quantile and the method of Blackburn et al. (1992), were significantly different from -0.681 , indicating that there is unlikely to be a constraint (sensu Brown and Maurer 1987) on the relationship between population density and body mass that is consistent with the EER. Instead, at higher population densities, the population density of a species is less influenced by body mass than would be expected if densities were being determined primarily based on energetics. Deviation from a linear negative scatterplot in our study results from the presence of many species that are either large and abundant or small and rare. Differences between tropical and temperate avian size-abundance relationships may be partly explained by differences in the trophic composition of the assemblages. Fifty-five percent of large, abundant species are frugivoreomnivores or granivores, two guilds poorly represented in the temperate zone, relative to tropical forests (Terborgh et al. 1990). The shallow slope and weak relationship for Amazonian birds also results from the presence of many small, rare species. In contrast to avian community structure in the temperate zone, the majority of species in the bird-rich assemblages of Neotropical forests are rare. In this Amazonian bird community, $43 \%$ of species occurred at average population densities below 5 individuals/100 ha, whereas in a temperate bird community in New Hampshire, U.S.A., only $21 \%$ of species were below this density (Holmes et al. 1986).

Other explanations may account for the deviation from the linear negative scatterplot displayed by this Amazonian bird community. Some studies suggest that the strong linear band of points observed in most global-level analyses may be composed of several smaller-scale relationships representing different taxonomic, guild, or spatial subsets having different slopes (Blackburn et al. 1990; Damuth 1991; Currie 1993; Blackburn and Gaston 1997; Schmid et al. 2000). Our finding that different guilds had different slopes of the size-abundance relationship both supports this explanation and agrees with the analyses of sizeabundance relationships for temperate birds that demonstrate differences among guilds (Newton 1979; Peters and Wassenberg 1983; Juanes 1986; Brown and Maurer 1987; Cotgreave and Harvey 1992).

Differences in the patterns observed at different scales may also result from the smaller body size range examined in smaller-scale studies, but as Currie (1993) observed, the 
smaller range of the independent variable should affect only the strength of the relationship, not its slope. Furthermore, many workers have advocated analyses of data sets representing natural assemblages (Blackburn et al. 1990, 1993a; Pagel et al. 1991), which are more likely to include rare species and be more representative of the range of true population densities than are global-scale studies (Pagel et al. 1991; Currie 1993). Natural assemblages have a relatively smaller range of body sizes. Nonetheless, testing whether the EER is a general rule of community structure, as Damuth $(1981,1987)$ originally described, necessitates analyses at the community level, especially if we are to uncover community-level mechanisms that may be shaping any resolved patterns.

Further examinations of the relationships among body mass, population density, and PEU in other tropical communities are necessary before we understand whether the patterns that we observed in this Amazonian bird community are representative and can be generalized to tropical bird communities as a whole. Further study also is needed before we can say whether there are fundamental differences in these patterns between tropical and temperate bird communities. Our findings indicate that whatever processes may be acting on larger scales to produce patterns consistent with the EER do not appear to be operating on smaller, community-level scales in this Amazonian bird community. Our findings also are consistent with other analyses at the community level, suggesting that the EER may not be a general rule of animal community structure, although it may have important biological significance at larger scales of observation.

\section{Acknowledgments}

We thank T. Garland, E. P. Martins, and C. L. Nunn for advice on analyses using phylogenetically independent contrasts. S. Aref, L. Fu, and X. He provided helpful statistical advice. E. J. Heske, T. J. Near, C. L. Nunn, and M. Wikelski provided insightful discussion of the ideas presented here and comments on earlier drafts. J. R. Eberhard kindly shared an unpublished phylogeny. K. P. Johnson and T. J. Near provided assistance assembling the phylogeny, which is available from S.E.R. upon request. This research was supported by the following grants: National Science Foundation (NSF) Graduate Student Fellowship to S.E.R., NSF grant DEV 8025975 to S.K.R., and NSF grant DEB-8207002 to J.T. Additional support was provided by the University of Illinois School of Integrative Biology.

\section{APPENDIX}

Literature Used to Construct Phylogenetic Hypothesis Used in Calculations of Independent Contrasts

Barker, F. K., and S. M. Lanyon. 2000. The impact of parsimony weighting schemes on inferred relationships among toucans and Neotropical barbets (Aves: Piciformes). Molecular Phylogenetics and Evolution 15: 215-234.

Burns, K. J. 1998. A phylogenetic perspective on the evolution of sexual dichromatism in tanagers (Thraupidae): the role of female versus male plumage. Evolution 52: 1219-1224.

Espinosa, D. L. M. A. 1998. Phylogenetic relationships among the trogons. Auk 115:937-954.

Griffiths, C. S. 1994. Monophyly of the Falconiformes based on syringeal morphology. Auk 111:787-805.

Hackett, S. J., and K. V. Rosenberg. 1990. Comparison of phenotypic and genetic differentiation in South American antwrens (Formicariidae). Auk 107:473-489.

Klicka, J., K. P. Johnson, and S. M. Lanyon. 2000. New World nine-primaried oscine relationships: constructing a mitochondrial DNA framework. Auk 117:321-336.

König, C., F. Weick, and J. Becking. 1999. Owls: a guide to the owls of the world. Yale University Press, New Haven, Conn.

Lanyon, S. M. 1985. A molecular perspective on higherlevel relationships in the Tyrannoidea (Aves). Systematic Zoology 34:404-418.

Lanyon, S. M., and R. M. Zink. 1987. Genetic variation in Piciform birds: monophyly and generic familial relationships. Auk 104:724-732.

Lanyon, W. E. 1984. A phylogeny of the kingbirds and their allies. American Museum Novitates 2797:1-28.

- 1988. A phylogeny of the flatbill and tody-tyrant assemblage of tyrant flycatchers. American Museum Novitates 2923:1-41.

- 1988. A phylogeny of the thirty-two genera in the Elaenia assemblage of tyrant flycatchers. American $\mathrm{Mu}-$ seum Novitates 2914:1-57.

McKitrick, M. C. 1985. Monophyly of the Tyrannidae (Aves): comparison of morphology and DNA. Systematic Zoology 34:35-45.

Miyaki, C. Y., S. R. Matioli, T. Burek, and A. Wajntal. 1998. Parrot evolution and paleogeographical events: mitochondrial DNA evidence. Molecular Biology and Evolution 15:544-551.

Prum, R. O., and W. E. Lanyon. 1989. Monophyly and phylogeny of the Schiffornis group (Tyrannoidea). Condor 91:444-461.

Raikow, R. J. 1994. A phylogeny of the woodcreepers (Dendrocolaptinae). Auk 111:104-114. 
Sibley, C. G., and J. E. Ahlquist. 1990. Phylogeny and classification of birds: a study in molecular evolution. Yale University Press, New Haven, Conn.

Sibley, C. G., and B. L. Monroe. 1990. Distribution and taxonomy of birds of the world. Yale University Press, New Haven, Conn.

\section{Literature Cited}

Abramsky, Z., M. L. Rosenzweig, and A. Subach. 2000. The energetic cost of competition: gerbils as moneychangers. Evolutionary Ecology Research 2:279-292.

- 2001. The cost of interspecific competition in two gerbil species. Journal of Animal Ecology 70:561-567.

Bartholomew, G. A., C. M. Vleck, and T. L. Bucher. 1983. Energy metabolism and nocturnal hypothermia in two tropical passerine frugivores, Manacus vitellinus and $\mathrm{Pi}$ pra mentalis. Physiological Zoology 56:370-379.

Bell, S. S., E. D. McCoy, and H. R. Muskinsky. 1991. Habitat structure: the physical arrangement of objects in space. Chapman \& Hall, New York.

Bennet, P. M., and P. H. Harvey. 1987. Active and resting metabolism in birds: allometry, phylogeny, and ecology. Journal of Zoology (London) 213:327-363.

Blackburn, T. M., and K. J. Gaston. 1997. A critical assessment of the form of the interspecific relationship between abundance and body size in animals. Journal of Animal Ecology 66:233-249.

Blackburn, T. M., P. H. Harvey, and M. D. Pagel. 1990. Species number, population density and body size relationships in natural communities. Journal of Animal Ecology 59:335-346.

Blackburn, T. M., J. H. Lawton, and J. N. Perry. 1992. A method of estimating the slope of upper bounds of plots of body size and abundance in natural animal assemblages. Oikos 65:107-112.

Blackburn, T. M., J. H. Lawton, and S. L. Pimm. $1993 a$. Non-metabolic explanations of the relationship between body size and animal abundance. Journal of Animal Ecology 62:694-702.

Blackburn, T. M., V. K. Brown, B. M. Double, J. J. D. Greenwood, J. H. Lawton, and N. E. Stork. 1993b. The relationship between abundance and body size in natural animal assemblages. Journal of Animal Ecology 62: 519-528.

Blackburn, T. M., S. Gates, J. H. Lawton, and J. J. D. Greenwood. 1994. Relations between body size, abundance and taxonomy of birds wintering in Britain and Ireland. Philosophical Transactions of the Royal Society of London B, Biological Sciences 343:135-144.

Blackburn, T. M., J. H. Lawton, and R. D. Gregory. 1996. Relationships between abundances and life histories of British birds. Journal of Animal Ecology 65:52-62.
Brawn, J. D., J. R. Karr, and J. D. Nichols. 1995. Demography of birds in a Neotropical forest: effects of allometry, taxonomy, and ecology. Ecology 76:41-51.

Brown, J. H., and B. A. Maurer. 1986. Body size, ecological dominance, and Cope's rule. Nature 324:248-250.

1987. Evolution of species assemblages: effects of energetic constraints and species dynamics on the diversification of the North American avifauna. American Naturalist 130:1-17.

Buchinsky, M. 2001. Recent advances in quantile regression models: a practical guideline for empirical research. Journal of Human Resources 33:1-126.

Burnham, K. P., and D. R. Anderson. 1998. Model selection and inference: a practical information-theoretic approach. Springer, New York.

Cade, B. S., J. W. Terrell, and R. L. Schroeder. 1999. Estimating effects of limiting factors with regression quantiles. Ecology 80:311-323.

Calder, W. A. 2000. Diversity and convergence: scaling for conservation. Pages 297-324 in J. H. Brown and G. B. West, eds. Scaling in biology. Oxford University Press, Oxford.

Carbone, C., and J. L. Gittleman. 2002. A common rule for the scaling of carnivore density. Science (Washington, D.C.) 295:2273-2276.

Case, T. J. 1979. Optimal body size and an animal's diet. Acta Biotheoretica 28:54-69.

Case, T. J., D. T. Bolger, and K. Petren. 1994. Invasions and competitive displacement among house geckos in the tropical Pacific. Ecology 75:464-477.

Cotgreave, P. 1993. The relationship between body size and population abundance in animals. Trends in Ecology \& Evolution 8:244-248.

- 1994. The relation between body size and abundance in a bird community: the effects of phylogeny and competition. Proceedings of the Royal Society of London B, Biological Sciences 256:147-149.

. 1995. Population density, body mass and niche overlap in Australian birds. Functional Ecology 9: 285-289.

Cotgreave, P., and P. H. Harvey. 1992. Relationships between body size, abundance and phylogeny in bird communities. Functional Ecology 6:248-256.

. 1994. Phylogeny and the relationship between body size and abundance in bird communities. Functional Ecology 8:219-228.

Croat, T. B. 1975. Phenological behavior of habitat classes on Barro Colorado Island (Panama Canal Zone). Biotropica 7:270-277.

Currie, D. J. 1993. What is the relationship between body size and population density? Oikos 66:353-358.

Daily, G. C., and P. R. Ehrlich. 1994. Influence of social 
status on individual foraging and community structure in a bird guild. Oecologia (Berlin) 100:153-165.

Damuth, J. 1981. Population density and body size in mammals. Nature 290:699-700.

1987. Interspecific allometry of population density in mammals and other animals: the independence of body mass and population energy use. Biological Journal of the Linnean Society 31:193-246.

- 1991. Of size and abundance. Nature 351: 268-269.

-1993. Cope's rule, the island rule and the scaling of mammalian population density. Nature 365:748-750.

Diaz-Uriarte, R., and T. Garland, Jr. 1996. Testing hypotheses of correlated evolution using phylogenetically independent contrasts: sensitivity to deviations from Brownian motion. Systematic Biology 45:27-47.

Dobson, G. P., and J. P. Headrick. 1995. Bioenergetic scaling: metabolic design and body size constraints in mammals. Proceedings of the National Academy of Sciences of the USA 92:7317-7321.

Draper, N. R., and H. Smith. 1998. Applied regression analysis. Wiley, New York.

Enquist, B. J., and K. J. Niklas. 2001. Invariant scaling relations across tree-dominated communities. Nature 410:655-660.

- 2002. Global allocation rules for patterns of biomass partitioning in seed plants. Science (Washington, D.C.) 295:1517-1520.

Enquist, B. J., J. H. Brown, and G. B. West. 1998. Allometric scaling of plant energetics and population density. Nature 395:163-165.

Enquist, B. J., G. B. West, E. L. Charnov, and J. H. Brown. 1999. Allometric scaling of production and life-history variation in vascular plants. Nature 401:907-911.

Felsenstein, J. 1985. Phylogenies and the comparative method. American Naturalist 125:1-15.

Foster, R. B. 1990. The floristic composition of the Rio Manú floodplain forest. Pages 99-111 in A. H. Gentry, ed. Four Neotropical forests. Yale University Press, New Haven, Conn.

Frankie, G. W., H. G. Baker, and P. A. Opler. 1974. Comparative phenological studies of trees in tropical wet and dry forests in the lowlands of Costa Rica. Journal of Ecology 62:881-919.

Garland, T., Jr., and A. R. Ives. 2000. Using the past to predict the present: confidence intervals for regression equations in phylogenetic comparative methods. American Naturalist 155:346-364.

Garland, T., Jr., P. H. Harvey, and A. R. Ives. 1992. Procedures for the analysis of comparative data using phylogenetically independent contrasts. Systematic Biology 41:18-32.

Gaston, K. J., and T. M. Blackburn. 1996. Range size-body size relationships: evidence of scale dependence. Oikos 75:479-485.

Gautier-Hion, A., and G. Michaloud. 1989. Are figs always keystone resources for tropical frugivorous vertebrates? a test in Gabon. Ecology 70:1826-1833.

Grafen, A. 1989. The phylogenetic regression. Philosophical Transactions of the Royal Society of London B, Biological Sciences 326:119-157.

Greenberg, R., D. K. Niven, S. Hopp, and C. Boone. 1993. Frugivory and coexistence in a resident and a migratory vireo on the Yucatan peninsula. Condor 95:990-999.

Greenwood, J. J. D., R. D. Gregory, S. Harris, P. A. Morris, and D. W. Yalden. 1996. Relations between abundance, body size, and species number in British birds and mammals. Philosophical Transactions of the Royal Society of London B, Biological Sciences 351:265-278.

Gregory, R. D. 1995. Phylogeny and relations among abundance, geographical range and body size of British breeding birds. Philosophical Transactions of the Royal Society of London B, Biological Sciences 349:345-351.

Griffiths, D. 1998. Sampling effort, regression method, and the shape and slope of size-abundance relations. Journal of Animal Ecology 67:795-804.

Hails, C. J. 1983. The metabolic rate of tropical birds. Condor 85:61-65.

Harvey, P. H., and M. D. Pagel. 1991. The comparative method in evolutionary biology. Oxford University Press, Oxford.

Harvey, P. H., and A. Rambaut. 1998. Phylogenetic extinction rates and comparative methodology. Proceedings of the Royal Society of London B, Biological Sciences 265:1691-1696.

He, X., and H. Liang. 2000. Quantile regression estimates for a class of linear and partially linear errors-invariables models. Statistica Sinica 10:129-140.

Holdridge, L. R. 1967. Life zone ecology. Occasional papers. Tropical Science Center, San José, Costa Rica.

Holmes, R. T., T. W. Sherry, and F. W. Sturges. 1986. Bird community dynamics in a temperate deciduous forest: long-term trends at Hubbard Brook (New Hampshire, USA). Ecological Monographs 56:201-220.

Howe, H. F. 1977. Bird activity and seed dispersal of a tropical wet forest tree. Ecology 58:539-550.

Illius, A. W., and I. J. Gordon. 1992. Modelling the nutritional ecology of ungulate herbivores: evolution of body size and competitive interactions. Oecologia (Berlin) 89:428-434.

Juanes, F. 1986. Population density and body size in birds. American Naturalist 128:921-929.

Kendeigh, S. C. 1944. Measurement of bird populations. Ecological Monographs 14:67-106.

Lasiewski, R. D., and W. R. Dawson. 1967. A re- 
examination of the relation between standard metabolic rate and body weight in birds. Condor 69:13-23.

Lawton, J. H. 1989. What is the relationship between population density and body size in animals? Oikos 55: 429-434.

Leighton, M. 1982. Fruit resources and patterns of feeding, spacing, and grouping among sympatric Bornean hornbills (Bucerotidae). Ph.D. diss. University of California, Davis.

Madansky, A. 1959. The fitting of straight lines when both variables are subject to error. Journal of the American Statistical Association 54:173-205.

Marquet, P. A. 2000. Invariants, scaling laws, and ecological complexity. Science (Washington, D.C.) 289:1487-1488.

Martins, E. P., and T. J. Garland. 1991. Phylogenetic analyses of the correlated evolution of continuous characters: a simulation study. Evolution 45:534-557.

Maurer, B. A. 1984. Interference and exploitation in bird communities. Wilson Bulletin 96:380-395.

Maurer, B. A., and J. H. Brown. 1988. Distribution of energy use and biomass among species of North American terrestrial birds. Ecology 69:1923-1932.

McArdle, B. H. 1988. The structural relationship: regression in biology. Canadian Journal of Zoology 66: 2329-2339.

McNab, B. K. 1986. The influence of food habits on the energetics of eutherian mammals. Ecological Monographs 56:1-20.

. 1988. Food habits and the basal rate of metabolism in birds. Oecologia (Berlin) 77:343-349.

- 2001. Energetics of toucans, a barbet, and a hornbill: implications for avian frugivory. Auk 118:916-933.

Morse, D. R., J. H. Lawton, and M. M. Dodson. 1985. Fractal dimension of vegetation and the distribution of arthropod body lengths. Nature 314:714-733.

Munn, C. A. 1985. Permanent canopy and understory flocks in Amazonia: species composition and population density. Pages 683-712 in P. A. Buckley, M. S. Foster, E. S. Morton, R. S. Ridgely, and F. G. Buckley, eds. Neotropical ornithology. American Ornithologists' Union, Washington, D.C.

Munn, C. A., and J. W. Terborgh. 1979. Multi-species territoriality in Neotropical foraging flocks. Condor 81: 338-347.

Nagy, K. A., I. A. Girard, and T. K. Brown. 1999. Energetics of free-ranging mammals, reptiles, and birds. Annual Review of Nutrition 19:247-277.

Nee, S., A. F. Read, J. J. D. Greenwood, and P. H. Harvey. 1991. The relationship between abundance and body size in British birds. Nature 351:312-313.

Newton, I. 1979. Population ecology of raptors. Buteo, Vermillion, S.Dak.

Opler, P. A., G. W. Frankie, and H. G. Baker. 1980. Com- parative phenological studies of treelet and shrub species in tropical wet and dry forests in the lowlands of Costa Rica. Journal of Ecology 68:167-188.

Pagel, M. D., P. H. Harvey, and H. C. J. Godfray. 1991. Species-abundance, biomass, and resource-use distributions. American Naturalist 138:836-850.

Peters, R. H. 1983. The ecological implications of body size. Cambridge University Press, New York.

Peters, R. H., and K. Wassenberg. 1983. The effect of body size on animal abundance. Oecologia (Berlin) 60:89-96.

Petren, K., and T. J. Case. 1996. An experimental demonstration of exploitation competition in an ongoing invasion. Ecology 77:118-132.

Petren, K., D. T. Bolger, and T. J. Case. 1993. Mechanisms in the competitive success of an invading sexual gecko over an asexual native. Science (Washington, D.C.) 259: 354-358.

Powell, G. V. N. 1979. Structure and dynamics of interspecific flocks in a Neotropical mid-elevation forest. Auk 96:375-390.

Pratt, T. K. 1984. Examples of tropical frugivores defending fruit-bearing plants. Condor 86:123-129.

Purvis, A., and A. Rambaut. 1995. Comparative analysis by independent contrasts (CAIC): an Apple Macintosh application for analysing comparative data. Computer Applications in the Biosciences 11:247-251.

Rayner, J. M. V. 1985. Linear relations in biomechanics: the statistics of scaling functions. Journal of Zoology (London) 206:415-440.

Remsen, J. V., Jr., M. A. Hyde, and A. Chapman. 1993. The diets of Neotropical trogons, motmots, barbets and toucans. Condor 95:178-192.

Reynolds, P. S., and R. M. Lee. 1996. Phylogenetic analysis of avian energetics: passerines and nonpasserines do not differ. American Naturalist 147:735-759.

Ritchie, M. E., and H. Olff. 1999. Spatial scaling laws yield a synthetic theory of biodiversity. Nature 400:557-560.

Robinson, S. K., and J. Terborgh. 1995. Interspecific aggression and habitat selection by Amazonian birds. Journal of Animal Ecology 64:1-11.

1997. Bird community dynamics along primary successional gradients of an Amazonian whitewater river. Pages 641-672 in J. V. Remsen, Jr., ed. Studies in Neotropical ornithology honoring Ted Parker. American Ornithologists' Union, Washington, D.C.

Santana, E. C., and B. G. Milligan. 1984. Behavior of toucanets, bellbirds, and quetzals feeding on Lauraceous fruits. Biotropica 16:152-154.

SAS Institute. 2000. The SAS system, release 8.1. SAS Institute, Cary, N.C.

Scharf, F. S., F. Juanes, and M. Sutherland. 1998. Inferring ecological relationships from the edges of scatter dia- 
grams: comparison of regression techniques. Ecology 79: 448-460.

Schleucher, E. 1999. Energy metabolism in an obligate frugivore, the superb fruit-dove (Ptilinopus superbus). Australian Journal of Zoology 47:169-179.

Schmid, P. E., M. Tokeshi, and A. J. M. Schmid. 2000. Relation between population density and body size in stream communities. Science (Washington, D.C.) 289: 1557-1560.

Sibley, C. G., and J. E. Ahlquist. 1990. Phylogeny and classification of birds: a study in molecular evolution. Yale University Press, New Haven, Conn.

Sibley, C. G., and B. L. Monroe, Jr. 1990. Distribution and taxonomy of birds of the world. Yale University Press, New Haven, Conn.

Siemann, E., D. Tilman, and J. Haarstad. 1996. Insect species diversity, abundance and body size relationships. Nature 380:704-706.

Sokal, R. R., and F. J. Rohlf. 1995. Biometry. W. H. Freeman, New York.

Stiles, F. G. 1975. Ecology, flowering phenology, and hummingbird pollination of some Costa Rican Heliconia species. Ecology 56:285-301.

Taper, M. L., and P. A. Marquet. 1996. How do species really divide resources? American Naturalist 147: 1072-1086.

Tellería, J. L., and L. M. Carrascál. 1994. Weight-density relationships between and within bird communities: im- plications of niche space and vegetation structure. American Naturalist 143:1083-1092.

Terborgh, J., and K. Petren. 1991. Development of habitat structure through succession in an Amazonian floodplain forest. Pages 28-46 in S. S. Bell, E. D. McCoy, and H. R. Muskinsky, eds. Habitat structure: the physical arrangement of objects in space. Chapman \& Hall, New York.

Terborgh, J., S. K. Robinson, T. A. Parker III, C. Munn, and N. Pierpont. 1990. Structure and organization of an Amazonian forest bird community. Ecological Monographs 60:213-238.

Vleck, C. M., and D. Vleck. 1979. Metabolic rate in five tropical bird species. Condor 81:89-91.

Weathers, W. W. 1979. Climatic adaptation in avian standard metabolic rate. Oecologia (Berlin) 42:81-90. . 1997. Energetics and thermoregulation by small passerines of the humid, lowland tropics. Auk 114: 341-353.

West, G. B., J. H. Brown, and B. J. Enquist. 1997. A general model for the origin of allometric scaling laws in biology. Science (Washington, D.C.) 276:122-126.

Wheelwright, N. T. 1985. Fruit size, gape width, and the diets of fruit-eating birds. Ecology 66:808-818.

Zar, J. H. 1996. Biostatistical analysis. Prentice Hall, Upper Saddle River, N.J. 